\title{
Adeno-Associated Virus Expression of $\alpha$-Synuclein as a Tool to Model Parkinson's Disease: Current Understanding and Knowledge Gaps
}

\author{
Taylor E. Huntington ${ }^{1,2}$, Rahul Srinivasan ${ }^{1,2^{*}}$ \\ ${ }^{1}$ Department of Neuroscience \& Experimental Therapeutics, Texas A\&M University College of Medicine, 8447 \\ Riverside Pkwy, Bryan, TX 77807, USA. ${ }^{2}$ Texas A\&M Institute for Neuroscience (TAMIN), College Station, \\ TX 77843, USA
}

[Received March 24, 2021; Revised May 15, 2021; Accepted May 16, 2021]

\begin{abstract}
Parkinson's disease (PD) is the second most common neurodegenerative disorder in the aging population and is characterized by a constellation of motor and non-motor symptoms. The abnormal aggregation and spread of alpha-synuclein ( $\alpha$-syn) is thought to underlie the loss of dopaminergic (DA) neurons in the substantia nigra pars compacta (SNc), leading to the development of PD. It is in this context that the use of adenoassociated viruses (AAVs) to express a-syn in the rodent midbrain has become a popular tool to model SNc DA neuron loss during PD. In this review, we summarize results from two decades of experiments using AAVmediated a-syn expression in rodents to model PD. Specifically, we outline aspects of AAV vectors that are particularly relevant to modeling a-syn dysfunction in rodent models of PD such as changes in striatal neurochemistry, a-syn biochemistry, and PD-related behaviors resulting from AAV-mediated a-syn expression in the midbrain. Finally, we discuss the emerging role of astrocytes in propagating a-syn pathology, and point to future directions for employing AAVs as a tool to better understand how astrocytes contribute to a-syn pathology during the development of PD. We envision that lessons learned from two decades of utilizing AAVs to express a-syn in the rodent brain will enable us to develop an optimized set of parameters for gaining a better understanding of how a-syn leads to the development of PD.
\end{abstract}

Key words: Parkinson's disease, alpha-synuclein, dopaminergic, model

Parkinson's disease (PD) is the second most common neurodegenerative disorder, affecting $1-2 \%$ of the population over 65 years. Clinically, PD is characterized by a loss of dopaminergic (DA) neurons in the substantia nigra pars compacta ( $\mathrm{SNc}$ ) and the onset of motor symptoms such as bradykinesia, resting tremors, postural instability, and muscle rigidity. Apart from motor symptoms, PD is also inundated with non-motor symptoms that occur before and during motor dysfunction, such as sleep disturbances, constipation, heightened sensitivity to pain, anxiety, depression, and cognitive dysfunction [1, 2]. These multifaceted clinical features correlate with a sequential degeneration of neurons within several discrete loci of the brain, which points to both spreading neuropathology and regional vulnerability as underlying causes for PD [3-7].

Rather than a single source of neurodegeneration, PD likely results from a few select factors with central roles in triggering the cascade of clinical presentations and spreading neuropathology. In this regard, the accumulation of Lewy bodies and Lewy neurites in the nigrostriatal pathway is a classic hallmark of clinical

*Correspondence should be addressed to: Dr. Rahul Srinivasan, Texas A\&M University College of Medicine, Department of Neuroscience \& Experimental Therapeutics, Bryan, TX 77807, USA. Email: rahul@ tamu.edu.

Copyright: () 2021 Huntington TE et al. This is an open-access article distributed under the terms of the Creative Commons Attribution License, which permits unrestricted use, distribution, and reproduction in any medium, provided the original author and source are credited. 
PD[8]. These distinctive histopathological features consist of an aggregation of $\sim 40$ different proteins with alpha-synuclein (a-syn) at its core[8]. Importantly, autopsies from PD patients with surgical grafts of mesencephalic DA neurons into the striatum show Lewy body inclusions that spread from the host tissue into exogenous DA grafts [9]. Together, these findings strongly implicate abnormal a-syn aggregation as an important nucleating factor for neurodegeneration during PD.

The idea that a-syn is a central player in the pathogenesis of $\mathrm{PD}$ has led to the development of molecular tools focused on understanding the mechanisms underlying a-syn-mediated neurodegeneration with the goal of discovering potential a-syn targeted therapeutics for PD. Consequently, at least three different tools have been developed to model the pathological features of a-syn in rodents. These tools include transgenic mice overexpressing a-syn, pre-formed a-syn fibrils (PFFs), and viral mediated overexpression with either adeno associated virus (AAV)- or lentivirus (LV) expressing a-syn. Each of these tools model distinct aspects of a-syn pathology in vivo, and recapitulates select symptoms of human PD.

In this review, we specifically focus on the use of AAV-mediated expression of a-syn as a tool to model PD in vivo. Over the past two decades, AAVs expressing asyn have provided an effective means to model the progressive loss of DA neurons in rodents and appear to model both early and late features of PD pathogenesis. However, studies from various groups using AAVs expressing a-syn have shown a range of outcomes from very slight to greater than $90 \%$ DA loss, leading to numerous choices when selecting the most appropriate parameters to model PD pathogenesis in rodents. We provide a detailed account of the observed differences in published studies, along with an informed perspective on how one could approach the use of AAVs to model PD in rodents. We also provide an overview of specific mechanisms by which a-syn can induce astrocytic dysfunction and DA loss during PD, which makes AAVs a valuable tool for expressing a-syn in astrocytes of the rodent brain.

\section{AAV-mediated a-syn overexpression in rodents as a tool to model PD}

The first step towards implicating a-syn in PD pathogenesis was the identification of a case of familial PD due to triplication of the SNCA gene that codes for asyn [10]. This finding was soon followed by the discovery that a-syn is a main component in Lewy bodies and Lewy neurites, which led to focused studies on the role of a-syn in PD [11].

Table 1 summarizes two decades of studies employing a unilateral injection of AAVs expressing human a-syn into the rodent SNc. The first studies utilizing AAV a-syn to model PD in rodents began in the early 2000's, with the demonstration that AAV2 is capable of robustly expressing a-syn in rat SNc DA neurons[12-14]. Subsequent studies showed that AAVmediated overexpression of WT or mutated (A53T, A30P) a-syn produces a progressive loss of DA neurons, motor deficits, and striatal dopamine loss. However, the time-course and extent of DA cell loss is highly variable [12-14]. Studies in male C57BL/6 mice display a similar wide variation in the extent of SNc DA neuron loss [1519]. The next sections discuss multifaceted consequences of AAV-mediated a-syn expression in rodents from a molecular, biochemical and behavioral standpoint, as well as the effects of phosphorylated a-syn (p-a-syn) and neuroinflammatory profiles observed with AAVmediated expression of a-syn.

Table 1. Table of studies utilizing unilateral AAV induction into the SNc of rodents for recapitulation of Parkinson's disease.

\begin{tabular}{|c|c|c|c|c|c|c|c|c|c|c|c|}
\hline Ref. & Animal/Sex & $\begin{array}{c}\text { Inj. Age } \\
\text { (wks) }\end{array}$ & Serotype & Promoter & $\begin{array}{l}\text { A-syn } \\
\text { Strain }\end{array}$ & Enhancers & $\begin{array}{l}\text { Viral Load } \\
\quad(\mathrm{gc})\end{array}$ & $\begin{array}{l}\text { Length of } \\
\text { expression }\end{array}$ & $\begin{array}{c}\text { TH loss } \\
\text { (SNc) }\end{array}$ & $\begin{array}{c}\text { TH loss } \\
\text { (STR) }\end{array}$ & $\begin{array}{l}\text { DA loss } \\
\text { (STR) }\end{array}$ \\
\hline [16] & SD Rats $-F$ & $* 8-12$ & AAV2/1 & CAG & A53T & $\begin{array}{c}\text { WPRE \& } \\
\text { bGF-polyA }\end{array}$ & $3.40 \mathrm{E}+09$ & $\begin{array}{l}3 \\
6 \\
\end{array}$ & $\begin{array}{l}\text { None } \\
-28 \% \\
\end{array}$ & $\begin{array}{c}-7 \% \\
-24.5 \% \\
\end{array}$ & $\begin{array}{l}\text { None } \\
-43 \% \\
\end{array}$ \\
\hline [22] & C57BL/6 - M & $* 8-10$ & AAV2/1 & $\mathrm{CMV}$ & WT & -- & $6.20 \mathrm{E}+08$ & $\begin{array}{c}4 \\
8 \\
12 \\
\end{array}$ & $\begin{array}{c}-- \\
-34 \% \\
-50 \% \\
\end{array}$ & $\begin{array}{l}-10 \% \\
-25 \% \\
-45 \% \\
\end{array}$ & $\begin{array}{c}-10 \% \\
-20-30 \% \\
-50-60 \%\end{array}$ \\
\hline [70] & C57BL/6 Pups & $\mathrm{P} 0$ & AAV2/1 & CAG & WT & WPRE & $2.70 \mathrm{E}+10$ & $\begin{array}{c}4 \\
12 \\
24 \\
\end{array}$ & -- & -- & -- \\
\hline [24] & C57BL/6 - M & 12 & AAV2/1 & CAG & A53T & $\begin{array}{c}\text { WPRE \& } \\
\text { bGF-polyA }\end{array}$ & $7.74 \mathrm{E}+09$ & 10 & $-30 \%$ & $-20 \%$ & $-38 \%$ \\
\hline [13] & SD Rats -M & 12 & AAV2/2 & $\mathrm{CAG}$ & $\mathrm{A} 30 \mathrm{P}$ & -- & $3.00 \mathrm{E}+10$ & 52 & $-53 \%$ & -- & -- \\
\hline [14] & SD Rats -M & 10 & AAV $2 / 2$ & CMV & WT & -- & $1.26 \mathrm{E}+09$ & 13 & $-49 \%$ & -- & $-10 \%$ \\
\hline
\end{tabular}




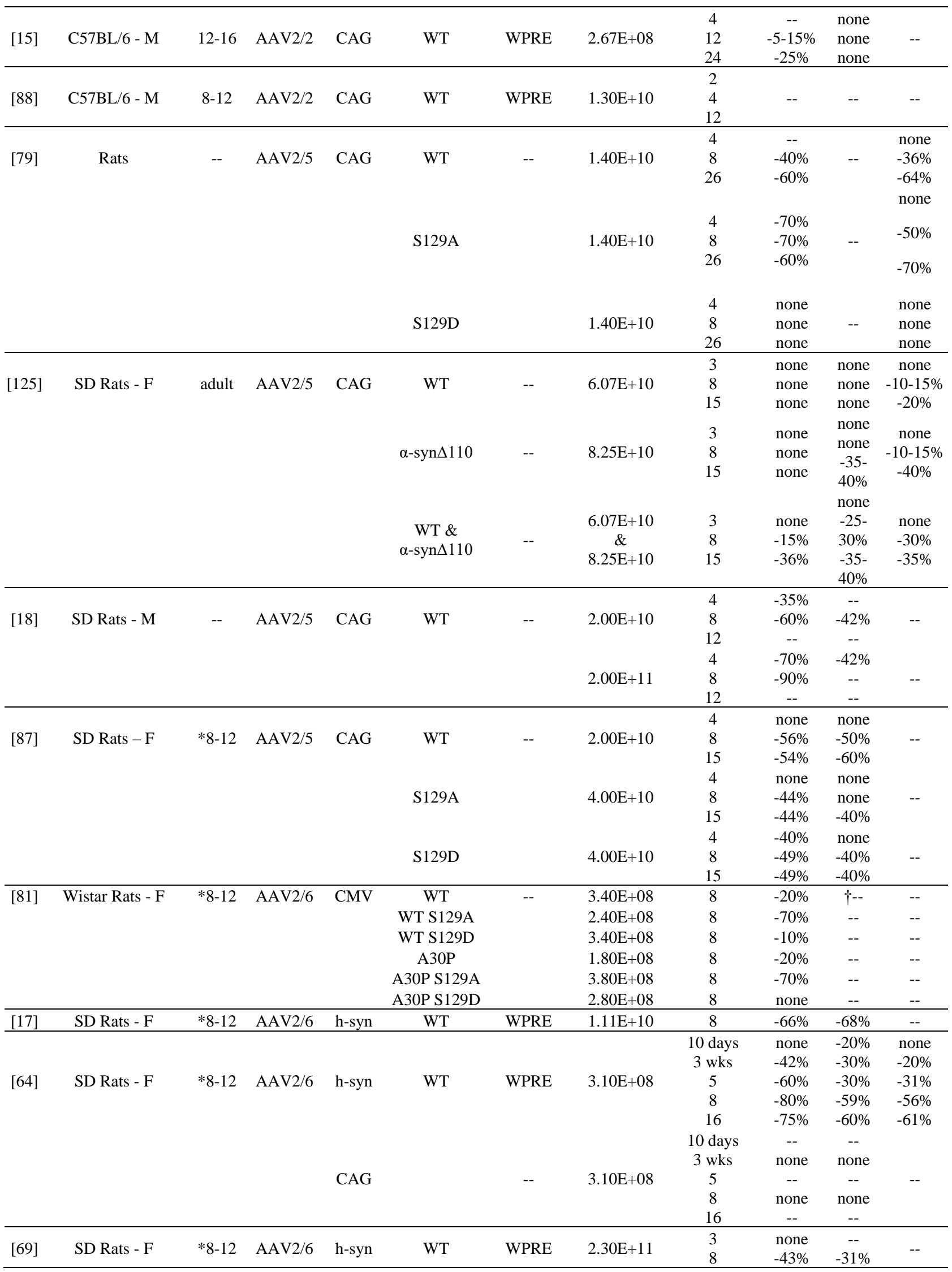




\begin{tabular}{|c|c|c|c|c|c|c|c|c|c|c|c|}
\hline$[25]$ & SD Rats - F & $* 8-12$ & AAV $2 / 6$ & PGK & WT & -- & $1.50 \mathrm{E}+07$ & 14 & $-45-50 \%$ & $\begin{array}{l}-25- \\
30 \%\end{array}$ & $-50 \%$ \\
\hline [62] & SD Rats - F & 16 & AAV $2 / 6$ & h-syn & WT & WPRE & $1.11 \mathrm{E}+10$ & 8 & $-50 \%$ & -- & $-60 \%$ \\
\hline [71] & SD Rats - F & $* 8-12$ & AAV $2 / 6$ & h-syn & WT & -- & $8.80 \mathrm{E}+08$ & $\begin{array}{c}7 \\
16 \\
28\end{array}$ & $\begin{array}{l}-10 \% \\
-30 \% \\
-50 \%\end{array}$ & $\begin{array}{c}-20- \\
25 \% \\
-30 \% \\
-40- \\
50 \% \\
\end{array}$ & -- \\
\hline$[65]$ & Wistar Rats - F & $* 8-12$ & AAV $2 / 7$ & $\begin{array}{l}\text { CMV-h- } \\
\text { syn }\end{array}$ & -- & $\mathrm{A} 53 \mathrm{~T}$ & $9.00 \mathrm{E}+08$ & $\begin{array}{c}15 \text { days } \\
29 \text { days } \\
11 \text { mo } \\
\end{array}$ & $\begin{array}{c}- \\
-80 \% \\
-- \\
\end{array}$ & -- & $\begin{array}{c}-60 \% \\
-92 \% \\
-- \\
\end{array}$ \\
\hline \multirow[t]{4}{*}{ [19] } & C57BL/6 - F & 8 & AAV2/7 & $\begin{array}{l}\text { CMV-h- } \\
\text { syn }\end{array}$ & WT & WPRE & $5.20 \mathrm{E}+08$ & $\begin{array}{c}5 \text { days } \\
4 \text { wks } \\
8\end{array}$ & $\begin{array}{c}- \\
-19 \% \\
-23 \%\end{array}$ & $\begin{array}{c}-- \\
-17 \% \\
-56 \%\end{array}$ & -- \\
\hline & & & & & WT & & $8.00 \mathrm{E}+08$ & $\begin{array}{c}5 \text { days } \\
4 \text { wks } \\
8\end{array}$ & $\begin{array}{c}-- \\
-45 \% \\
-50 \%\end{array}$ & $\begin{array}{c}-- \\
-56 \% \\
-86 \%\end{array}$ & -- \\
\hline & & & & & WT & & $1.60 \mathrm{E}+09$ & $\begin{array}{c}5 \text { days } \\
4 \text { wks } \\
8\end{array}$ & $\begin{array}{c}-- \\
-57 \% \\
-82 \%\end{array}$ & $\begin{array}{c}-- \\
-73 \% \\
-86 \%\end{array}$ & -- \\
\hline & & & & & A53T & & $8.00 \mathrm{E}+08$ & $\begin{array}{c}5 \text { days } \\
4 \text { wks } \\
8 \\
\end{array}$ & $\begin{array}{c}-- \\
-51 \% \\
-59 \% \\
\end{array}$ & $\begin{array}{c}-- \\
-57 \% \\
-91 \% \\
\end{array}$ & -- \\
\hline [23] & SD Rats - M & $8-10$ & AAV2/9 & h-syn & WPRE & WT & $4.00 \mathrm{E}+09$ & $\begin{array}{l}1 \\
4 \\
\end{array}$ & $\begin{array}{c}- \\
-57 \% \\
\end{array}$ & $\begin{array}{c}- \\
-60 \% \\
\end{array}$ & $\begin{array}{l}-- \\
-70 \% \\
\end{array}$ \\
\hline$[66]$ & $\begin{array}{l}\text { C57BL/6 - M } \\
\text { SAMR1 - M } \\
\text { SAMP8 - M }\end{array}$ & $8-10$ & AAV2/9 & $\begin{array}{l}\text { CMV-h- } \\
\text { syn }\end{array}$ & $\mathrm{A} 53 \mathrm{~T}$ & -- & $8.40 \mathrm{E}+08$ & 20 & $\begin{array}{l}-30 \% \\
\text { none } \\
\text { none }\end{array}$ & $\begin{array}{l}-25- \\
30 \% \\
-30 \% \\
-30 \%\end{array}$ & $\begin{array}{l}-- \\
-- \\
--\end{array}$ \\
\hline [190] & SD Rats $-F$ & 8 & AAV2/9 & $\mathrm{CAG}$ & $\mathrm{A} 53 \mathrm{~T}$ & -- & $1.16 \mathrm{E}+10$ & 10 & $-55 \%$ & -- & -- \\
\hline [191] & $\begin{array}{c}\text { Fisher } 344 \text { Rats - } \\
\text { M }\end{array}$ & 12 & AAV2/9 & CAG & WT & $\begin{array}{l}\text { WPRE \& } \\
\text { bGF-polyA }\end{array}$ & $4.40 \mathrm{E}+09$ & $\begin{array}{c}2 \\
4 \\
16\end{array}$ & $\begin{array}{c}\text { none } \\
-25-30 \% \\
-25-30 \%\end{array}$ & -- & -- \\
\hline
\end{tabular}

When a study did not report a parameter (--) is used. When a study reported either no or non-significant changes in a parameter, none, is used. Columns/Abbreviations: Ref. (reference), rodent strain and sex (M/F), age at injection, AAV serotype, promotor, strain of a-syn, enhancing elements, viral load injected in total genomic copies, length of expression of a-syn, loss of tyrosine hydroxylase (TH) neurons in the SNc, TH loss in the striatum, dopamine (DA) loss in the striatum. *age as determined by average weight reported. † As measured by TH and VMAT2.

\section{Biochemical and molecular changes}

Based on amino acid (aa) composition, a-syn has three distinct domains, with an amphipathic N-terminal domain (aa 1-60), a central hydrophobic domain (aa 61-94), and an acidic C-terminal domain (aa 95-140). a-syn mainly localizes to pre-synaptic terminals $[20,21]$, where the amphipathic and central domains mediate a-syn interactions with cellular membranes. These interactions result in distinct biochemical and molecular changes during PD.

$\mathrm{AAV}$-mediated a-syn expression in rodents causes a paradoxical increase in dopamine turnover along with a depletion of the dopamine transporter, DAT [16, 17, 2225]. In addition, a dynamic change in DAT binding occurs between 3 and 6 weeks post injection, beginning with a $31 \%$ increase and ending with a $48 \%$ decrease in DAT binding [16]. This would suggest that early stages of asyn pathology may be associated with a paradoxical increase in striatal dopamine. Indeed, 4-month old male transgenic mice overexpressing a-syn under the Thy-1 promoter also show a surge in dopamine release within the striatum[26]. Following this initial surge in striatal dopamine, rodents show a loss of the axonal terminals of $\mathrm{SNc}$ DA neurons in the striatum [26], which is accompanied with a decrease in striatal dopamine as well as its major metabolites, 3,4-dihydroxyphenylacetic acid (DOPAC) and homovanillic acid (HVA). These findings are similar to previous studies in patients with PD showing an initial degeneration of DA axons in the striatum [27], and relates to an increased risk of PD in humans with DAT mutations [28]. This suggests that AAV-mediated a-syn expression in the rodent $\mathrm{SNc}$ reliably models clinical aspects of PD related to fluctuations in striatal dopamine.

Dysfunctions in striatal dopamine also trigger increases in burst firing within the subthalamic nucleus (STN). In PD patients, this is typically seen during surgical implantation of deep brain stimulation electrodes into the STN and is also noted in PD toxin models [2932]. One study overexpressing a-syn using AAV2/5CAG-WT-a-syn-WPRE in the SNc has recapitulated heightened burst firing within the STN of female Sprague Dawley (SD) rats [33], suggesting that AAV-mediated a- 
syn pathology in the $\mathrm{SNc}$ can have wide-ranging consequences that lead to dysfunction of other basal ganglia nuclei.

Within the pre-synaptic compartment, a-syn interactions with SNARE protein complexes as well as with the vesicular transporter of monoamines (VMAT2) have been described [34-37], suggesting a primary role for a-syn in the trafficking and assembly of synaptic vesicle complexes[38-40]. In support of this idea, all known point mutations in a-syn associated with familial PD (A30P, E46K, H50Q, G51D, A53T, and A53E) localize to the Nterminus, suggesting that alterations in the ability of a-syn to bind to cellular membranes may underlie its toxic effects, and trigger abnormal aggregation of a-syn [4150].

Interactions between a-syn and multiple cellular and subcellular targets $[34,51,52]$ are also mediated by the core region of this intrinsically disordered protein. The central, hydrophobic region of a-syn (aa 61-94) was first identified in amyloid plaques of Alzheimer's disease patients [44]. Termed the non-amyloid- $\beta$ component (NAC), conformational changes in this region are responsible for a-syn fibril formation and aggregation due to crosslinking of $\beta$-sheets [53-57]. Indeed, the idea that a-syn may exist in a dynamic equilibrium between a disordered monomer and a tetramer under physiological conditions [58-61] would indicate that changes in both regions could abnormally alter monomer:tetramer a-syn ratios. This may be due to either an inability of a-syn to bind to membranes, an abnormal increase in a-syn binding to membranes or result in abnormal a-syn aggregates and the formation of Lewy pathology. Further understanding of a-syn structure in humans and in AAV-mediated expression in rodents are needed to determine the full relationship of a-syn structure and pathology in PD.

\section{Behavioral changes}

The early pre-symptomatic stage following AAVmediated expression of a-syn in rodents correlates with early striatal dysfunction [17, 22, 62, 63], which could precede non-motor behavioral changes reminiscent of prodromal symptoms such as anxiety or depression. During the symptomatic stage, the extent of DA neuron loss and consequent deficits in striatal dopamine are large enough to induce motor dysfunction $[12,13,18,19,23$, 64-67], while the more advanced stages are likely characterized by an increase in mortality. Therefore, depending on the exact model, AAV-mediated a-syn expression in the $\mathrm{SNc}$ can recapitulate important aspects of early, mid as well as late stages of clinical PD.

The most widely tested behavior among all PD models is locomotion. In AAV models with a unilateral injection of AAV-a-syn, behavioral paradigms that focus on measuring motor asymmetry such as amphetamine or apomorphine induced rotations, cylinder test, or pawstepping test are commonly employed [13]. In addition, the beam walk, open field, and rotarod test are also common behavioral tests for AAV-a-syn models [18, 19, $23,65,66,68-70]$. Although the vast majority of AAV studies show motor deficits compared to controls, there is variability in the amount of SNc dopaminergic loss when correlated with motor symptoms. A majority of AAVbased studies report motor deficits only when greater than $50 \%$ of SNc DA neurons are lost, which is consistent with clinical PD [12, 13, 17-19, 23, 65-67]. However, several other studies show motor deficits with less than $40 \% \mathrm{SNc}$ DA neuron loss $[16,17,24,25,68,71,72]$. As shown in Table 1, potential sources for this variability are numerous and could include differences in behavioral assays, in the methodology used for quantification of PD-related behaviors, the AAV serotype, length of time for expression of a-syn or species of rodent. Studies focused on systematically comparing one or more of these parameters are therefore essential for developing a more consistent and standardized AAV-based a-syn expression model for PD in rodents.

An array of non-motor symptoms appears prior to motor dysfunction and are attributed to both DA and nonDA neuron pathology. These symptoms include sleep disturbances, depression, anxiety, cognitive dysfunction, heightened pain, hallucinations, impaired color vision, and hyposmia [1, 73-75]. A few AAV a-syn models in rodents have assessed non-motor symptoms in PD [18, 67-69]. Male AAV-a-syn SD rats show significant loss in odor discrimination at 9 weeks, followed by significant deficits in rotarod performance [67]. In a recent study, female SD rats unilaterally injected with AAV-a-syn showed anxiety, but no cognitive deficits. A similar anxiety phonotype has been reported in male Wistar rats with bilateral SNc injection of AAV a-syn [68]. Additionally, gastrointestinal (GI) disturbances have been associated with a-syn pathology in the gut-brain axis [76, 77], but only two studies so far have explored the ability of AAV-a-syn in modeling this feature of PD [78]. Thus, AAV-mediated expression of a-syn in the rodent $\mathrm{SNc}$ appears to model important aspects of PD such as anxiety, and GI dysfunction. However, not all prodromal symptoms may be present in AAV a-syn PD models. Further characterization of non-motor symptoms in PD such as depression, cognitive dysfunction and hyposmia is necessary. This would be especially beneficial when investigated with AAV-a-syn models already shown to reproduce DA neurodegeneration and motor symptoms.

Phosphorylated a-syn (p-a-syn) 
The C-terminus of a-syn (aa 96-140) is a highly unstructured region with several post-translational modification sites, including phosphorylation sites (Tyr$125,133,136$ and Ser-129). This region is populated with negatively charged amino acids resulting in a random coil structure at the tail of a-syn. The most common posttranslational modification is phosphorylation of a-syn at S129 (p-a-syn). Interestingly, p-a-syn is expressed throughout the brain in PD patients, and in PFF and AAV a-syn models of PD [67, 79, 80]. This suggests that phosphorylation of S129 is pathological. In accordance with this idea, abundant expression of p-a-syn is accompanied by bulging neurite morphology in the striatum and a dystrophic morphology of cell bodies in the SNc of AAV a-syn expressing rodents [19, 33, 65, 70]. Further evidence for a pathological role of p-a-syn comes from the finding that $\mathrm{p}$-a-syn comprises greater than $90 \%$ of LBs seen in post-mortem human tissue. Attempts in AAV studies to further characterize $\mathrm{p}$-a-syn inclusions consist of proteinase $\mathrm{K}$ digestion, immuno-staining for ubiquitin or thioflavin $S$, or a combination $[16,24,67,71$, 72, 80-83]. A recent study bilaterally overexpressing A53T a-syn demonstrated a shorter half-life for p-a-syn and increased concentrations of $\mathrm{p}$-a-syn with proteasome inhibition, indicating p-a-syn as a favored substrate in the ubiquitin-proteome system [84]. Additionally, lysosome and autophagosome-like structures demarcated in the inner architecture of LBs suggest dysfunction in degradation pathways [85].

Rodent models of AAV-a-syn expression provide the advantage of expressing a-syn with aa substitutions that mimic either a phosphorylated (S129D) or a dephosphorylated (S129A) form of the protein. The dephosphorylated state of S129, in some AAV rat models, correlates with higher rates of DA cell death in both WT and A30P strains [79, 86]. However, another study using a different rat strain reported slower DA cell loss with S129A expression [87]. In order to better understand the role of S129 a-syn phosphorylation in PD, differences in experimental parameters such as AAV serotype, viral titers, and strain of rodents used will need to be systematically addressed in a standardized setting.

\section{Neuroinflammation}

In AAV a-syn models, the overexpression of WT or mutant a-syn activates microglia and induces lymphocyte infiltration. Neuroinflammatory markers such as IL-6, TNF- $\alpha$, and CD68 are upregulated, along with production of $\mathrm{CD}^{+}$and $\mathrm{CD}^{+} \mathrm{T}$ lymphocytes $[65,72,80,88,89]$. Interestingly, partial rescue of DA neurodegeneration occurs with pharmacological inhibition of upregulated angiotensin II type I receptors in an AAV $\alpha$-syn rat model
[23]. While microglia are the resident immune cell in the CNS, recent evidence points to a larger role for astrocytes in neuroinflammation than previously thought, particularly with regard to a-synucleinopathies $[90,91]$. It is important to note that although AAVs provide a useful model for studying neuroinflammation during PD, GFPexpressing AAVs injected into the rodent hippocampus have been shown to induce astrocyte reactivity at high titers [92]. Therefore, one has to be cautious with regard to the serotype and titer of the AAV being used to express a-syn. In summary, rodent models utilizing AAVmediated a-syn expression parallel several aspects of PD pathology including neurochemical changes, non-motor and motor behaviors, and neuroinflammatory changes in the brain.

\section{Changes in organelle function}

Apart from the pre-synaptic terminal, potent membrane binding capabilities of a-syn have also been identified in organelles such as mitochondria [38, 52, 93, 94], the endoplasmic reticulum $[95,96]$, the Golgi apparatus[9799] and the nucleus [100]. Multiple forms of a-syn disrupt protein synthesis and degradation pathways, restrict intracellular calcium handling, increase oxidative stress, and impair phagocytic activity $[52,101]$.

AAV a-syn models demonstrate aggregates localizing to mitochondria associated membranes [38, 39]. This disrupts $\mathrm{Ca}^{2+}$ handling from $\mathrm{ER}$ to mitochondria and ATP production, and alters energetic homeostasis in the brain [102, 103]. Additionally, a-syn interactions with calcium-ATPases lead to fragmentation in the Golgi apparatus [52]. Mutations in genes implicated in PD have direct consequences on mitochondrial function, but are exacerbated with accumulation of a-syn aggregates [104, 105]. In neurons, region specific decreases in respiratory chain complexes correlate with idiopathic PD in humans [103]. However, another study showed higher levels of respiratory complexes without a change in the number of neuronal mitochondria [106]. a-syn further elicits subcellular damage in the nucleus via interactions with DNA and histones that are thought to impact production of vesicular transport machinery [52]. Furthermore, a-syn degradation is mediated by the ubiquitin-proteasome system and the autophagy-lysosomal system; however, recent studies have revealed damages to these systems that may encourage a-syn aggregation [83, 84, 107, 108]. Taken together, these reports suggest diverse roles for asyn in subcellular function with the potential for abnormal a-syn to exert global pathological effects on neuronal physiology. The vast majority of organelle interactions have been studied in neurons [5, 52], but emerging evidence shows parallel mechanisms of a-syn induced pathology in glial organelles, including astrocytes [109, 
110]. Understanding how these mechanisms affect PD pathogenesis will greatly enhance our knowledge of PD, and neurodegeneration in general.

\section{An analysis of AAVs as viral vectors for expressing a-syn}

Recombinant AAVs are multi-functional tools in research and are widely used for gene delivery to the central nervous system (CNS) of rodents as well as humans [27, 111]. Advantages of recombinant AAVs include their low immunopathogenicity and the episomal expression of transgenes, with a very low probability of integration into the host genome [112]. Moreover, the ability of AAVs to transduce slow-dividing or non-dividing cells in a targeted manner is beneficial for expressing proteins in different cell types within the CNS. Together, these features make AAVs an attractive tool to express a-syn as a means to understand how pathological a-syn initiates PD. As shown in Table 1, key elements of AAVs that vary among rodent a-syn studies include the genome with promoter and enhancer elements, capsid serotype, the strain of a-syn encoded, method of purification, and determination of functional titer. In addition, the choice of control AAVs for experiments along with the species, strain, age, and sex of rodents significantly influence the outcome of studies in terms of the extent of SNc DA neurodegeneration. In the next sections, we consider each of these elements in some detail.

\section{AAV genome}

Recombinant AAVs are classified based on their genomic sequence and capsid serotype. Thus, AAV2/5 denotes a recombinant AAV with an AAV2 genomic sequence and an AAV5 capsid serotype. The AAV genome typically consists of a transgene cDNA cassette and a polyadenylation signal driven by a promoter for tissue/cell specific expression. Enhancers and/or posttranscriptional elements can be added within the cassette for optimized transgene expression. AAV expression systems are compatible with a wide range of minimal promoters and enhancers for transgene expression. This not only increases flexibility in altering a-syn expression, but also gives rise to increased variability in modeling asyn pathology. Some common minimal promoters used in AAV a-syn models include the cytomegalovirus (CMV), chicken beta-actin (CBA), human synapsin I (hSyn or Syn-1), phosphoglycerate kinase 1 (PGK), cytomegalovirus-enhanced synapsin I (CMVie/hSyn), and the chicken beta actin/cytomegalovirus enhancer hybrid (CAG). Although these promoters efficiently transduce DA neurons in the $\mathrm{SNc}[17,65,113]$, how these promoters influence the subsequent cell-to-cell transfer of a-syn has not been completely elucidated. In addition to minimal promoters, the Woodchuck Hepatitis Virus Posttranscriptional Regulatory Element (WPRE) is commonly included in AAV-a-syn expression systems. WPRE consistently produces robust dopaminergic loss compared to AAVs with no WPRE [64]. On the other hand, the presence of WPRE does not ensure cell death as other studies report lower dopaminergic degeneration despite higher injected viral titer [24, 69]. Thus, although promoter and enhancer elements can influence the outcome of experiments with a-syn expression, the mechanisms underlying these variations remain to be determined.

\section{AAV capsid}

In rodents, AAV2/2 shows low transduction efficiency; however, studies employing AAV 2/1, 2/5, 2/6, 2/7, 2/8, and $2 / 9$ in the CNS show a marked improvement in terms of transduction efficiency [114-118]. In a separate study, Aschauer and colleagues determined that AAV 2/5, 2/8, and 2/9 show increased transgene expression in striatum, hippocampus, and auditory cortex of adult mice when compared to AAV 2/1 [119]. Furthermore, transduction efficiencies of AAV 2/1 and 2/5 are higher in adult mouse tissue than in neonatal brains, and transduction efficiency has been shown to change over time in neonatal mice $[116,118,120]$. Apart from the AAV serotype, the species of rodent used (mice versus rats) may play a role in determining AAV expression efficiency. Interestingly, models utilizing AAV 2/1 and AAV2/7 show dose dependent nigral cell death with WT and A53T a-syn overexpression in rodents $[16,19]$. However, a comparison shows AAV 2/1 expressing the A53T mutant a-syn promotes greater DA degeneration in rats than in mice[16, 24]. These unknown interactions between AAV serotypes and rodent species point to species-specific differences that may include either permissivity to AAV infection, immune responses, or genetic differences between mice and rats.

Apart from influencing the rate of DA degeneration in vivo, AAV capsid serotypes can alter other factors such as transduction volume, cell tropism, and even the retrograde transport of AAV-expressed proteins [121, 122]. While AAVs are able to transduce larger areas of tissue than PFFs, a lower transduction volume with AAV2/8 was reported in rats [114]. This appears to be a function of the AAV2/8 serotype since a lower AAV2/8 transduction volume was also observed in adult mouse brains; however, this deficit disappeared with an increase in viral titer [116]. Interestingly, some AAVs may be more efficient at the retrograde transport of AAVexpressed proteins in neurons. In a study comparing seven different serotypes, only AAV2/5 was able to transduce 
SNc neurons after striatal injection, while Burger et al. reported both AAV2/1 and 2/5 enhance the retrograde transport of expressed proteins $[115,123]$.

Despite phenotypic variations in terms of PD-related behaviors following AAV-mediated a-syn expression, the majority of AAV a-syn studies report greater than $80 \%$ AAV-mediated a-syn expression in SNc dopaminergic neurons. Further characterization of AAV capsid serotype transduction efficiencies in mature rodent brains will benefit efforts to consistently reproduce a-syn pathology. Also, the approval of multiple AAV serotype capsids for use in humans (AAV 1,2, and 9) may provide insight on whether or not lessons learned from AAV-mediated transgene expression in rodents are applicable to humans $[111,124]$.

\section{$A A V$ purification and titer}

Potential sources for variability between AAV studies come from the AAV purification method used as well as the method to determine functional viral titers, which have been previously described [80]. Importantly, the method used to purify AAVs for in vivo injection could alter the functional titer, which is determined by the proportion of empty AAV capsids or AAV genome copies that are not encapsulated, both of which will be incapable of protein expression in vivo [125]. Since most AAV titers are determined via DNA dot blot or by qPCR, which do not report functional titers, better and more efficient methods to determine the functional titers or AAVs will need to be developed. Undoubtedly, advancements in AAV quality control and improvements in vector transduction efficiencies will lead to a newer generation of AAVs rodent models that consistently mimic key aspects of asyn pathology in PD patients [27].

3. Appropriate controls, age, species, and sex differences in modeling AAV-mediated a-syn pathology in rodents

Following unilateral AAV injection into the rodent brain, there is significant spread to the contralateral hemisphere which makes it difficult to utilize the uninjected side as a control [126]. Furthermore, bilateral injections of AAVa-syn to model PD in rodents are rarely employed[22, 69, 70]. Therefore, many studies utilize separate injections of control AAVs as empty vectors or encoding fluorescent reporters such as GFP or mCherry (Table 1). Since high titers AAV-GFP induce toxicity [16, 92, 112], proteins that form non-toxic oligomers, such as actin or collagen, might serve as a better control for AAV a-syn overexpression models [112].

Age is a critical factor when considering parameters when designing AAV-mediated a-syn expression experiments in rodents. Evidence for an influence of age on a-syn expression in vivo comes from a number of studies. Decreases in endogenous a-syn levels are present in 20-month old, but not in 10- and 2- month old male C57BL/6 mice [127]. Conversely, humans and nonhuman primates show increased a-syn levels with age [128]. Indeed, all human brain cell types exhibit changes in gene expression levels upon aging[129]. The effect of age on AAV a-syn-induced DA cell death has been compared between C57BL/6, and two outbred strains which are the rapid aging, SAMP8 and the age resistant, SAMR1 mice. Surprisingly, only C57BL/6 mice experienced cell death, indicating possible background susceptibilities or compensatory mechanisms, rather than age dependent a-syn pathology [66]. Similar differences related to strains are observed in rats. Specifically, Wistar rats are less susceptible to DA cell death when compared to Sprague Dawley (SD) rats [66].

A heavy species bias exists towards the use of SD rats as AAV a-syn models (Table 1). A specific preference for SD rats stems from the relative ease of performing behavioral paradigms in rats, the differential gene expression between species, and technical challenges related to injection of AAVs into the mouse SNc [130]. Surprisingly, there is also a sex bias towards the use of female SD rats, while male C57BL/6 mice are the chosen sex for AAV a-syn mouse models (Table 1). In humans, males are diagnosed with PD at a higher rate than women, and clinical symptoms have been shown to vary with sex $[131,132]$. Given the central importance of sex differences in PD, future studies will need to focus on assessing differences in AAV-mediated a-syn expression, DA cell death, and PD-related behaviors between male and female rodents.

\section{Additional tools to model a-syn pathology PD in rodents}

Since the implication of a-syn in neurodegenerative diseases including Parkinson's disease, Lewy body dementia, and multiple system atrophy, numerous molecular tools and animal models have been developed to study underlying mechanisms and efficacy of potential therapeutics. Although the vast majority of a-syn models utilize either transgenic mice, exogenous oligomers or PFFs, or viral vectors, recent data using combinations of these tools to induce PD has begun to show promise [71, 133]. In this case, each PD model varies in rate of a-syn spreading, degree of pathogenicity, and time course of PD progression.

Transgenic mice expressing either the mutant or wildtype strains of human a-syn were the first animal models to overexpress a-syn[134-136]. These models shows very little to no neurodegeneration in DA neurons of the 
$\mathrm{SNc}$ [137], but they do show neuronal inclusions similar to LB seen in human PD, as well as deficits in striatal dopamine, neuroinflammation, and prodromal behaviors including cognitive, sleep, and olfactory dysfunctions [1, $73,138,139]$. Despite these caveats, a-syn overexpressing transgenic mice likely reflect pathological processes that occur before the onset of neurodegeneration, which makes this approach a useful tool to study the role of a-syn dysfunction during early-stage PD. Moreover, the expression of a-syn aggregates in transgenic mice may be a useful model for determining the efficacy of therapeutics in mediating or even reversing a-syn aggregation.

The use of oligomers or PFFs, either injected into the brain [71, 140, 141], or into the gut [76, 142] is a second tool that has recently gained traction and is increasing our understanding of the nature of a-syn spread within the brain. PFFs cause robust DA cell death and show extensive spread of a-syn pathology across brain regions $[100,143,144]$. Ser-129 phosphorylation of endogenous a-syn in response to extracellular a-syn fibrils exerts profound effects on the ability of a-syn to form toxic aggregates[143], and may be of particular relevance to the spread of a-syn pathology across brain regions. Injection of exogenous a-syn fibrils can elicit an immune response in microglia not present with monomeric a-syn [145]. Similar to AAV-mediated a-syn, PFF injections are regionally targeted and typically unilateral [146]. PFFs also mirror the widespread variability among results (DA neurodegeneration, changes in striatal dopamine, motor deficits) seen in AAV a-syn models $[71,80,146]$. Differences in size and structural homogeneity of PFFs cause variability in results. However, recent advancements in standardizing PFF generation and characterization will help overcome this barrier. Thus, PFF a-syn rodent models offer distinct insights into the seeding and propagation of toxic species in asynucleinopathies, and a unique perspective of $\mathrm{PD}$ pathogenesis.

While we focus on AAV-mediated a-syn models in this review, the use of other viral vectors in rodents have also enabled an understanding of a-syn pathology. Lentiviruses (LVs) have genomes that are roughly twice as large as AAVs, allowing for a larger payload. However, disadvantages of LVs include lower transduction efficiency, higher toxicity, and viral incorporation into the host genome [147]. There are relatively fewer studies utilizing LVs that demonstrate large variabilities in DA neurodegeneration [148-151]. The formation of neuronal, cytosolic inclusions in LV a-syn models have been exploited to test efficacy of PD treatments such as parkin, glial-derived neurotropic factor (GDNF), or heat shock protein overexpression $[152,153]$. Furthermore, in vivo LV overexpression of mutated a-syn has shown that oligomeric a-syn is a critical determinant of the degree of a-syn-induced pathology [151]. This inherent toxicity and the probability of spontaneous recombination have been mitigated with newer generations of LVs [154, 155]. Thus, LVs have indeed become useful tools in gene therapy developments as well as therapy efficacy [155]. Importantly, the payload of LVs allows for the study of larger PD-related genes such as LRRK2[147]. While current a-syn models favor the use of AAVs, the use of LVs to confirm therapeutic efficacy, promote gene therapy, and understand the mechanisms of PD relevant genes is critical for understanding PD from multiple perspectives.

In summary, no one tool is able to fully recapitulate the molecular and behavioral pathogenesis of a-syn seen in human PD, but selecting the appropriate tool will allow greater accuracy in modeling specific aspects of PD pathology. Furthermore, combinations of these aforementioned tools are beginning to show promise in recapitulating the complexities of human a-syn pathology $[71,133,140,156]$.

\section{Using AAVs to understand the role of astrocyte- specific a-syn in PD}

Astrocytes govern important aspects of brain function such as glutamate clearance, extracellular $\mathrm{K}^{+}$buffering, regulation and maintenance of the blood brain barrier, the release of antioxidants and gliotransmitters, and synaptic physiology [157-159]. Interestingly, many of the genes implicated in the progression of PD, such as ATP13A2, GBA1, LRRK2, PARK7, PINK1 and PARKIN are highly expressed in human astrocytes [22, 160-162], and human post-mortem brain studies, in vitro, as well as in vivo models of a-syn [90] suggest a significant role for astrocytes in a-syn pathology. Together, these reports suggest that astrocytes play a critical role in the pathogenesis of $\mathrm{PD}$, and in the propagation of a-syn pathology during later stages of the disease.

There is some evidence that a-syn may have a physiological role in astrocytes that is distinct from its role in neurons. Astrocytes alter gene expression in response to a-syn aggregates [163], and primary astrocytes from SNCA KO mice display disrupted incorporation of fatty acids arachidonic acid and palmitic acid, which indicates a possible physiological role for the low amounts of endogenous a-syn in astrocytes [161]. Conversely, the overaccumulation of a-syn in astrocytes elicits both a loss of physiological functions and gain of toxic, inflammatory functions. Despite evidence for a-syn function in astrocytes, AAV a-syn models have not focused on astrocytes. In the next sections, we highlight key findings that are relevant to a-syn pathology in astrocytes and astrocyte dysfunction in AAV-a-syn based models. We 
also discuss potential caveats for studying astrocytes using AAV-mediated a-syn expression.

\section{Astrocytic uptake and transfer of a-syn}

Astrocytic inclusions containing aggregated a-syn have been observed in post-mortem brain samples of PD patients $[3,161,164]$ and in human derived astrocyte cultures [104, 162, 165-167]. One theory is that astrocytes take up a-syn following extracellular secretion by neurons, which results in the formation of abnormal inclusions of a-syn in astrocytes. In support of this idea, different mechanisms of astrocytic uptake of a-syn in rodents using in vitro and in vivo models have been proposed [90, 168-170]. Following uptake by astrocytes or neurons, a-syn transfer may occur via prion-like spreading $[39,168]$, tunneling nanotubes $[166,171,172]$, exosomes [173], or by endocytosis of dead neurons [174, 175]. Interestingly, Loria et al established that in neuron and astrocyte co-cultures, the fibrillary form of a-syn can be transferred from neuron to astrocyte, astrocyte to astrocyte, but not from astrocyte to neuron [167]. In the same study, fluorescently labelled a-syn fibrils localized to astrocytic and neuronal lysosomal compartments for degradation in vitro; however, only astrocyte and microglial cells showed lysosomes containing a-syn in organotypic cultures, consistent with other a-syn models [167]. Thus, astrocytes appear to not only contain abnormal a-syn during PD, but may also possess specialized mechanisms for the internalization and degradation of a-syn, which makes these cells a potentially important, but understudied cell type in the context of PD.

\section{Potential astrocyte dysfunctions from a-syn pathology}

Studies have also begun to elucidate potential mechanisms that underlie astrocyte dysfunction in asynucleinopathies. One interesting finding in this regard is that the abnormal accumulation of a-syn in astrocytes results in altered glutamate clearance [176]. Utilizing a transgenic mouse model with mutant A53T and WT a-syn directly targeted to astrocytes, another study has shown that the astrocytic glutamate transporters, GLT-1 and GLAST were downregulated [177]. In support of these previous studies, oligomeric a-syn from erythrocytederived extracellular vesicles of PD patients has been shown to co-localize with GLT-1 in astrocytes and is associated with a reduction in glutamate clearance, possibly due to the inhibition of GLT1 function [170].These findings together suggest that a-syn accumulation in astrocytes can significantly alter glutamate neurotransmission in the brain, which has important implications for neurodegeneration.
Finally, the role of astrocytes in neuroinflammation has only recently become an area of intense focus. Astrocytes actively participate in the degradation and clearance of a-syn [178]. Oligomeric and nonfibrillized asyn deposition in astrocytes lead to activation of microglia in vitro[179] and in vivo $[102,177]$. Moreover, release of cytokines such as TNF- $\alpha$ and IL- $\beta$ from astrocytes initiate apoptosis in dopaminergic neurons[180]. In advanced stages of neurodegeneration, astrocytes are reactive and engulf a-syn aggregates, synapses, and dead cells [91]. Analogously, in healthy murine astrocytes, overaccumulation of amyloid-beta triggers an immune response [181]. Yet, neuroinflammation in the AAV a-syn model has largely been investigated in the context of microglia.

In sum, a large body of evidence suggests that astrocytes play a critical role in the pathogenesis of PD, and particularly in the pathological effects of a-syn. Targeting AAV-a-syn to astrocytes can therefore serve as a valuable tool to model the specific effects of a-syn on astrocytic function in vivo. In this regard, several AAV serotypes are capable of astrocyte transduction, including AAV 2/1, 2/5, 2/8, and 2/9 [118, 119, 182-185]. Recently, AAV $2 / 6$ was shown to preferentially transduce astrocytes (>90\%) in the barrel cortex of male SD rats[186], but none of the studies employing AAV 2/6 in Table 1 report expression of a-syn in GFAP labeled astrocytes. The use of AAV compatible astrocyte-specific minimal promoters such as GFaABC1D[187, 188] or the use of Flex AAV constructs to express a-syn in large populations of astrocytes from astrocyte-specific Cre mice [189] can provide novel insights into the role of astrocytes in propagating a-syn pathology. In addition, using signal sequences that target a-syn to subcellular organelles such as astrocytic mitochondria[188] could allow us to study how a-syn affects subcellular compartments of astrocytes with unprecedented precision.

\section{Conclusion}

Based on two decades of experiments, we now know that the expression of a-syn with AAVs in rodents recapitulates several aspects of $\mathrm{PD}$. AAV-mediated a-syn expression causes defects in striatal neurochemistry that precede SNc DA loss, induces the formation of phosphorylated $\alpha$-syn aggregates throughout the nigrostriatal pathway, and results in neuroinflammation as well as the activation of glia. AAVs possess a plethora of customizable features that include promoters, enhancers, inclusion of fluorescent tags, and serotype of viral capsid in which the construct is packaged. While the expression of a-syn using AAVs in rodents has undeniably expanded our understanding of the molecular pathology in PD and other a-synucleinopathies, the very same customizable 
features that make AAVs an attractive model, have also led to inconsistencies between various studies. Undoubtedly, future advancements in AAV quality control and improvements in vector transduction efficiencies will lead to a newer generation of AAVs rodent models that consistently mimic the key aspects of a-syn pathology in PD patients. Based on the emerging role of astrocytes during PD pathogenesis, an exciting new direction in PD research would be to apply AAVs as a tool to specifically understand the role of astrocytes in propagating a-syn pathology. We envision that lessons learned from two-decades of experiments utilizing AAVa-syn to model PD in rodents will enable us to apply this knowledge towards understanding the critical role of astrocytes in propagating a-syn pathology during PD.

\section{Acknowledgements}

Supported by a National Science Foundation (NSF) Graduate Research Fellowship Program (GRFP) award to TEH and a National Institutes of Health (NIH) research grant (R01 NS115809) to RS.

\section{Conflict of interest statement}

Authors declare no competing financial interests.

\section{References}

[1] Schapira AHV, Chaudhuri KR, Jenner P (2017). Nonmotor features of Parkinson disease. Nature Reviews Neuroscience, 18:435-450.

[2] Faivre F, Joshi A, Bezard E, Barrot M (2019). The hidden side of Parkinson's disease: Studying pain, anxiety and depression in animal models. Neurosci Biobehav Rev, 96:335-352.

[3] Braak H, Sastre M, Del Tredici K (2007). Development of alpha-synuclein immunoreactive astrocytes in the forebrain parallels stages of intraneuronal pathology in sporadic Parkinson's disease. Acta Neuropathol, 114:231-241.

[4] Pellicano C, Benincasa D, Pisani V, Buttarelli FR, Giovannelli M, Pontieri FE (2007). Prodromal nonmotor symptoms of Parkinson's disease. Neuropsychiatric Disease and Treatment, 3:145-152.

[5] Mahlknecht P, Seppi K, Poewe W The Concept of Prodromal Parkinson's Disease. Journal of Parkinson's Disease, 5:681-697.

[6] Prell T (2018). Structural and Functional Brain Patterns of Non-Motor Syndromes in Parkinson's Disease. Frontiers in Neurology, 9.

[7] Giguère N, Burke Nanni S, Trudeau L-E (2018). On Cell Loss and Selective Vulnerability of Neuronal Populations in Parkinson's Disease. Frontiers in Neurology, 9.

[8] Mahul-Mellier A-L, Burtscher J, Maharjan N,
Weerens L, Croisier M, Kuttler F, et al. (2020). The process of Lewy body formation, rather than simply $\alpha$ synuclein fibrillization, is one of the major drivers of neurodegeneration. Proceedings of the National Academy of Sciences, 117:4971-4982.

[9] Li W, Englund E, Widner H, Mattsson B, van Westen $\mathrm{D}$, Lätt J, et al. (2016). Extensive graft-derived dopaminergic innervation is maintained 24 years after transplantation in the degenerating parkinsonian brain. Proceedings of the National Academy of Sciences of the United States of America, 113:6544-6549.

[10] Polymeropoulos MH, Lavedan C, Leroy E, Ide SE, Dehejia A, Dutra A, et al. (1997). Mutation in the alpha-synuclein gene identified in families with Parkinson's disease. Science (New York, N.Y.), 276:2045-2047.

[11] Spillantini MG, Crowther RA, Jakes R, Hasegawa M, Goedert M (1998). alpha-Synuclein in filamentous inclusions of Lewy bodies from Parkinson's disease and dementia with lewy bodies. Proceedings of the National Academy of Sciences of the United States of America, 95:6469-6473.

[12] Kirik D, Rosenblad C, Burger C, Lundberg C, Johansen T, Muzyczka N, et al. (2002). ParkinsonLike Neurodegeneration Induced by Targeted Overexpression of $\alpha$-Synuclein in the Nigrostriatal System. The Journal of Neuroscience, 22:2780-2791.

[13] Klein RL, King MA, Hamby ME, Meyer EM (2002). Dopaminergic cell loss induced by human A30P alphasynuclein gene transfer to the rat substantia nigra. Hum Gene Ther, 13:605-612.

[14] Yamada M, Iwatsubo T, Mizuno Y, Mochizuki H (2004). Overexpression of alpha-synuclein in rat substantia nigra results in loss of dopaminergic neurons, phosphorylation of alpha-synuclein and activation of caspase-9: resemblance to pathogenetic changes in Parkinson's disease. J Neurochem, 91:451461 .

[15] Martin JLS, Klucken J, Outeiro TF, Nguyen P, KellerMcGandy C, Cantuti-Castelvetri I, et al. (2007). Dopaminergic neuron loss and up-regulation of chaperone protein mRNA induced by targeted overexpression of alpha-synuclein in mouse substantia nigra. Journal of Neurochemistry, 100:1449-1457.

[16] Koprich JB, Johnston TH, Huot P, Reyes MG, Espinosa M, Brotchie JM (2011). Progressive neurodegeneration or endogenous compensation in an animal model of Parkinson's disease produced by decreasing doses of alpha-synuclein. PLoS One, 6:e17698.

[17] Decressac M, Mattsson B, Bjorklund A (2012). Comparison of the behavioural and histological characteristics of the 6-OHDA and alpha-synuclein rat models of Parkinson's disease. Exp Neurol, 235:306315.

[18] Gombash SE, Manfredsson FP, Kemp CJ, Kuhn NC, Fleming SM, Egan AE, et al. (2013). Morphological and behavioral impact of AAV2/5-mediated overexpression of human wildtype alpha-synuclein in the rat nigrostriatal system. PLoS One, 8:e81426. 
[19] Oliveras-Salvá M, Van der Perren A, Casadei N, Stroobants S, Nuber S, D'Hooge R, et al. (2013). rAAV2/7 vector-mediated overexpression of alphasynuclein in mouse substantia nigra induces protein aggregation and progressive dose-dependent neurodegeneration. Molecular Neurodegeneration, 8:44.

[20] Diao J, Burré J, Vivona S, Cipriano DJ, Sharma M, Kyoung M, et al. (2013). Native $\alpha$-synuclein induces clustering of synaptic-vesicle mimics via binding to phospholipids and synaptobrevin-2/VAMP2. eLife, 2:e00592.

[21] Larsen KE, Schmitz Y, Troyer MD, Mosharov E, Dietrich P, Quazi AZ, et al. (2006). -Synuclein Overexpression in PC12 and Chromaffin Cells Impairs Catecholamine Release by Interfering with a Late Step in Exocytosis. Journal of Neuroscience, 26:11915-11922.

[22] Song LK, Ma KL, Yuan YH, Mu Z, Song XY, Niu F, et al. (2015). Targeted Overexpression of alphaSynuclein by rAAV2/1 Vectors Induces Progressive Nigrostriatal Degeneration and Increases Vulnerability to MPTP in Mouse. PLoS One, 10:e0131281.

[23] Rodriguez-Perez AI, Sucunza D, Pedrosa MA, Garrido-Gil P, Kulisevsky J, Lanciego JL, et al. (2018). Angiotensin Type 1 Receptor Antagonists Protect Against Alpha-Synuclein-Induced Neuroinflammation and Dopaminergic Neuron Death. Neurotherapeutics, 15:1063-1081.

[24] Ip CW, Klaus LC, Karikari AA, Visanji NP, Brotchie JM, Lang AE, et al. (2017). AAV1/2-induced overexpression of A53T-alpha-synuclein in the substantia nigra results in degeneration of the nigrostriatal system with Lewy-like pathology and motor impairment: a new mouse model for Parkinson's disease. Acta Neuropathol Commun, 5:11.

[25] Daniel G, Musso A, Tsika E, Fiser A, Glauser L, Pletnikova O, et al. (2015). alpha-Synuclein-induced dopaminergic neurodegeneration in a rat model of Parkinson's disease occurs independent of ATP13A2 (PARK9). Neurobiol Dis, 73:229-243.

[26] Lam HA, Wu N, Cely I, Kelly RL, Hean S, Richter F, et al. (2011). Elevated tonic extracellular dopamine concentration and altered dopamine modulation of synaptic activity precede dopamine loss in the striatum of mice overexpressing human $\alpha$-synuclein. Journal of Neuroscience Research, 89:1091-1102.

[27] Domenger C, Grimm D (2019). Next-generation AAV vectors-do not judge a virus (only) by its cover. Hum Mol Genet, 28:R3-R14.

[28] Vingill S, Connor-Robson N, Wade-Martins R (2018). Are rodent models of Parkinson's disease behaving as they should? Behav Brain Res, 352:133-141.

[29] Alonso-Frech F, Zamarbide I, Alegre M, RodríguezOroz MC, Guridi J, Manrique M, et al. (2006). Slow oscillatory activity and levodopa-induced dyskinesias in Parkinson's disease. Brain: A Journal of Neurology, 129:1748-1757.

[30] Remple MS, Bradenham CH, Kao CC, Charles PD,
Neimat JS, Konrad PE (2011). Subthalamic Nucleus Neuronal Firing Rate Increases with Parkinson's Disease Progression. Movement disorders : official journal of the Movement Disorder Society, 26:16571662.

[31] Brazhnik E, Novikov N, McCoy AJ, Cruz AV, Walters JR (2014). Functional Correlates of Exaggerated Oscillatory Activity in Basal Ganglia Output in Hemiparkinsonian Rats. Experimental neurology, 261:563-577.

[32] Galvan A, Devergnas A, Wichmann T (2015). Alterations in neuronal activity in basal gangliathalamocortical circuits in the parkinsonian state. Frontiers in Neuroanatomy, 9.

[33] Andersen MA, Sotty F, Jensen PH, Badolo L, Jeggo R, Smith GP, et al. (2019). Long-Term Exposure to PFE360 in the AAV- $\alpha$-Synuclein Rat Model: Findings and Implications. eNeuro, 6 .

[34] Burré J, Sharma M, Südhof TC (2018). Cell Biology and Pathophysiology of $\alpha$-Synuclein. Cold Spring Harbor Perspectives in Medicine, 8:a024091.

[35] Guo Jing L, Covell Dustin J, Daniels Joshua P, Iba M, Stieber A, Zhang B, et al. (2013). Distinct $\alpha$-Synuclein Strains Differentially Promote Tau Inclusions in Neurons. Cell, 154:103-117.

[36] Swant J, Goodwin JS, North A, Ali AA, GambleGeorge J, Chirwa S, et al. (2011). $\alpha$-Synuclein stimulates a dopamine transporter-dependent chloride current and modulates the activity of the transporter. The Journal of Biological Chemistry, 286:4393343943.

[37] Wersinger C, Rusnak M, Sidhu A (2006). Modulation of the trafficking of the human serotonin transporter by human alpha-synuclein. The European Journal of Neuroscience, 24:55-64.

[38] Guardia-Laguarta C, Area-Gomez E, Rub C, Liu Y, Magrane J, Becker D, et al. (2014). alpha-Synuclein is localized to mitochondria-associated ER membranes. J Neurosci, 34:249-259.

[39] Dehay B, Fernagut PO (2016). Alpha-synuclein-based models of Parkinson's disease. Rev Neurol (Paris), 172:371-378.

[40] Fischer DL, Gombash SE, Kemp CJ, Manfredsson FP, Polinski NK, Duffy MF, et al. (2016). Viral VectorBased Modeling of Neurodegenerative Disorders: Parkinson's Disease. Methods Mol Biol, 1382:367382.

[41] Singleton AB, Farrer M, Johnson J, Singleton A, Hague S, Kachergus J, et al. (2003). $\alpha$-Synuclein Locus Triplication Causes Parkinson's Disease. Science, 302:841-841.

Chartier-Harlin M-C, Kachergus J, Roumier C, Mouroux V, Douay X, Lincoln S, et al. (2004). Alphasynuclein locus duplication as a cause of familial Parkinson's disease. Lancet (London, England), 364:1167-1169.

[43] Segrest JP, Loof HD, Dohlman JG, Brouillette CG, Anantharamaiah GM (1990). Amphipathic helix motif: Classes and properties. Proteins: Structure, Function, and Bioinformatics, 8:103-117. 
[44] Uéda K, Fukushima H, Masliah E, Xia Y, Iwai A, Yoshimoto M, et al. (1993). Molecular cloning of cDNA encoding an unrecognized component of amyloid in Alzheimer disease. Proceedings of the National Academy of Sciences of the United States of America, 90:11282-11286.

[45] Bussell R, Eliezer D (2003). A Structural and Functional Role for 11-mer Repeats in $\alpha$-Synuclein and Other Exchangeable Lipid Binding Proteins. Journal of Molecular Biology, 329:763-778.

[46] Ulmer TS, Bax A, Cole NB, Nussbaum RL (2005). Structure and dynamics of micelle-bound human alpha-synuclein. The Journal of Biological Chemistry, 280:9595-9603.

[47] Jao CC, Hegde BG, Chen J, Haworth IS, Langen R (2008). Structure of membrane-bound $\alpha$-synuclein from site-directed spin labeling and computational refinement. Proceedings of the National Academy of Sciences, 105:19666-19671.

[48] Bodner CR, Dobson CM, Bax A (2009). Multiple tight phospholipid-binding modes of alpha-synuclein revealed by solution NMR spectroscopy. Journal of Molecular Biology, 390:775-790.

[49] Fusco G, De Simone A, Gopinath T, Vostrikov V, Vendruscolo M, Dobson CM, et al. (2014). Direct observation of the three regions in $\alpha$-synuclein that determine its membrane-bound behaviour. Nature Communications, 5:3827.

[50] Martial B, Lefèvre T, Buffeteau T, Auger M (2019). Vibrational Circular Dichroism Reveals Supramolecular Chirality Inversion of $\alpha$-Synuclein Peptide Assemblies upon Interactions with Anionic Membranes. ACS nano, 13:3232-3242.

[51] Meade RM, Fairlie DP, Mason JM (2019). Alphasynuclein structure and Parkinson's disease - lessons and emerging principles. Molecular Neurodegeneration, 14:29.

[52] Bernal-Conde LD, Ramos-Acevedo R, ReyesHernández MA, Balbuena-Olvera AJ, MoralesMoreno ID, Argüero-Sánchez R, et al. (2020). AlphaSynuclein Physiology and Pathology: A Perspective on Cellular Structures and Organelles. Frontiers in Neuroscience, 13.

[53] George JM (2002). The synucleins. Genome Biology, 3:reviews3002.3001-reviews3002.3006.

[54] Giasson BI, Murray IV, Trojanowski JQ, Lee VM (2001). A hydrophobic stretch of 12 amino acid residues in the middle of alpha-synuclein is essential for filament assembly. The Journal of Biological Chemistry, 276:2380-2386.

[55] Breydo L, Wu JW, Uversky VN (2012). A-synuclein misfolding and Parkinson's disease. Biochimica Et Biophysica Acta, 1822:261-285.

[56] Rodriguez JA, Ivanova MI, Sawaya MR, Cascio D, Reyes FE, Shi D, et al. (2015). Structure of the toxic core of $\alpha$-synuclein from invisible crystals. Nature, 525:486-490.

[57] Tuttle MD, Comellas G, Nieuwkoop AJ, Covell DJ, Berthold DA, Kloepper KD, et al. (2016). Solid-state NMR structure of a pathogenic fibril of full-length human $\alpha$-synuclein. Nature Structural \& Molecular Biology, 23:409-415.

[58] Bartels T, Choi JG, Selkoe DJ (2011). alpha-Synuclein occurs physiologically as a helically folded tetramer that resists aggregation. Nature, 477:107-110.

[59] Wang W, Perovic I, Chittuluru J, Kaganovich A, Nguyen LTT, Liao J, et al. (2011). A soluble $\alpha$ synuclein construct forms a dynamic tetramer. Proceedings of the National Academy of Sciences of the United States of America, 108:17797-17802.

[60] Fauvet B, Mbefo MK, Fares M-B, Desobry C, Michael $\mathrm{S}$, Ardah MT, et al. (2012). $\alpha$-Synuclein in central nervous system and from erythrocytes, mammalian cells, and Escherichia coli exists predominantly as disordered monomer. The Journal of Biological Chemistry, 287:15345-15364.

[61] Nuber S, Rajsombath M, Minakaki G, Winkler J, Müller CP, Ericsson M, et al. (2018). Abrogating Native $\alpha$-Synuclein Tetramers in Mice Causes a LDOPA-Responsive Motor Syndrome Closely Resembling Parkinson's Disease. Neuron, 100:7590.e75.

[62] Tozzi A, de Iure A, Bagetta V, Tantucci M, Durante V, Quiroga-Varela A, et al. (2016). Alpha-Synuclein Produces Early Behavioral Alterations via Striatal Cholinergic Synaptic Dysfunction by Interacting With GluN2D N-Methyl-D-Aspartate Receptor Subunit. Biol Psychiatry, 79:402-414.

[63] Van der Perren A, Van den Haute C, Baekelandt V. 2014. Viral Vector-Based Models of Parkinson's Disease. In Behavioral Neurobiology of Huntington's Disease and Parkinson's Disease. H.H.P. Nguyen, and M.A. Cenci, editors. Berlin, Heidelberg: Springer Berlin Heidelberg. 271-301.

[64] Decressac M, Mattsson B, Lundblad M, Weikop P, Bjorklund A (2012). Progressive neurodegenerative and behavioural changes induced by AAV-mediated overexpression of alpha-synuclein in midbrain dopamine neurons. Neurobiol Dis, 45:939-953.

[65] Van der Perren A, Toelen J, Casteels C, Macchi F, Van Rompuy AS, Sarre S, et al. (2015). Longitudinal follow-up and characterization of a robust rat model for Parkinson's disease based on overexpression of alpha-synuclein with adeno-associated viral vectors. Neurobiol Aging, 36:1543-1558.

[66] Bourdenx M, Dovero S, Engeln M, Bido S, Bastide MF, Dutheil N, et al. (2015). Lack of additive role of ageing in nigrostriatal neurodegeneration triggered by alpha-synuclein overexpression. Acta Neuropathol Commun, 3:46.

[67] Niu H, Shen L, Li T, Ren C, Ding S, Wang L, et al. (2018). Alpha-synuclein overexpression in the olfactory bulb initiates prodromal symptoms and pathology of Parkinson's disease. Transl Neurodegener, 7:25.

[68] Campos FL, Carvalho MM, Cristovao AC, Je G, Baltazar G, Salgado AJ, et al. (2013). Rodent models of Parkinson's disease: beyond the motor symptomatology. Front Behav Neurosci, 7:175.

[69] Caudal D, Alvarsson A, Bjorklund A, Svenningsson P 
(2015). Depressive-like phenotype induced by AAVmediated overexpression of human alpha-synuclein in midbrain dopaminergic neurons. Exp Neurol, 273:243-252.

[70] Delenclos M, Faroqi AH, Yue M, Kurti A, CastanedesCasey M, Rousseau L, et al. (2017). Neonatal AAV delivery of alpha-synuclein induces pathology in the adult mouse brain. Acta Neuropathol Commun, 5:51.

[71] Thakur P, Breger LS, Lundblad M, Wan OW, Mattsson B, Luk KC, et al. (2017). Modeling Parkinson's disease pathology by combination of fibril seeds and alpha-synuclein overexpression in the rat brain. Proc Natl Acad Sci U S A, 114:E8284-E8293.

[72] Ulusoy A, Febbraro F, Jensen PH, Kirik D, RomeroRamos M (2010). Co-expression of C-terminal truncated alpha-synuclein enhances full-length alphasynuclein-induced pathology. Eur J Neurosci, 32:409422.

[73] McDowell K, Chesselet M-F (2012). Animal models of the non-motor features of Parkinson's disease. Neurobiology of disease, 46:597-606.

[74] Kalia LV, Lang AE (2016). Evolving basic, pathological and clinical concepts in PD. Nature Reviews Neurology, 12:65-66.

[75] Tibar H, El Bayad K, Bouhouche A, Ait Ben Haddou EH, Benomar A, Yahyaoui M, et al. (2018). NonMotor Symptoms of Parkinson's Disease and Their Impact on Quality of Life in a Cohort of Moroccan Patients. Frontiers in Neurology, 9.

[76] Kim S, Kwon S-H, Kam T-I, Panicker N, Karuppagounder SS, Lee S, et al. (2019). Transneuronal Propagation of Pathologic $\alpha$-Synuclein from the Gut to the Brain Models Parkinson's Disease. Neuron.

[77] Schaeffer E, Kluge A, Böttner M, Zunke F, Cossais F, Berg D, et al. (2020). Alpha Synuclein Connects the Gut-Brain Axis in Parkinson's Disease Patients - A View on Clinical Aspects, Cellular Pathology and Analytical Methodology. Frontiers in Cell and Developmental Biology, 8:573696.

[78] Ulusoy A, Phillips RJ, Helwig M, Klinkenberg M, Powley TL, Di Monte DA (2017). Brain-to-stomach transfer of $\alpha$-synuclein via vagal preganglionic projections. Acta Neuropathologica, 133:381-393.

[79] Gorbatyuk OS, Li S, Sullivan LF, Chen W, Kondrikova G, Manfredsson FP, et al. (2008). The phosphorylation state of Ser-129 in human alphasynuclein determines neurodegeneration in a rat model of Parkinson disease. Proceedings of the National Academy of Sciences of the United States of America, 105:763-768.

[80] Volpicelli-Daley LA, Kirik D, Stoyka LE, Standaert DG, Harms AS (2016). How can rAAV-alphasynuclein and the fibril alpha-synuclein models advance our understanding of Parkinson's disease? J Neurochem, 139 Suppl 1:131-155.

[81] Azeredo da Silveira S, Schneider BL, Cifuentes-Diaz C, Sage D, Abbas-Terki T, Iwatsubo T, et al. (2008). Phosphorylation Does Not Prompt, Nor Prevent, the Formation of -synuclein Toxic Species in a Rat Model of Parkinson's Disease. Human Molecular Genetics.

[82] Taschenberger G, Garrido M, Tereshchenko Y, Bähr M, Zweckstetter M, Kügler S (2012). Aggregation of $\alpha$ Synuclein promotes progressive in vivo neurotoxicity in adult rat dopaminergic neurons. Acta Neuropathologica, 123:671-683.

[83] Chung E, Choi Y, Park J, Nah W, Park J, Jung Y, et al. (2020). Intracellular delivery of Parkin rescues neurons from accumulation of damaged mitochondria and pathological $\alpha$-synuclein. Science Advances, 6:eaba1193.

[84] McKinnon C, De Snoo ML, Gondard E, Neudorfer C, Chau H, Ngana SG, et al. (2020). Early-onset impairment of the ubiquitin-proteasome system in dopaminergic neurons caused by $\alpha$-synuclein. Acta Neuropathologica Communications, 8:17.

[85] Hoffmann A-C, Minakaki G, Menges S, Salvi R, Savitskiy S, Kazman A, et al. (2019). Extracellular aggregated alpha synuclein primarily triggers lysosomal dysfunction in neural cells prevented by trehalose. Scientific Reports, 9:544.

[86] Azeredo da Silveira S, Schneider BL, Cifuentes-Diaz C, Sage D, Abbas-Terki T, Iwatsubo T, et al. (2009). Phosphorylation does not prompt, nor prevent, the formation of alpha-synuclein toxic species in a rat model of Parkinson's disease. Hum Mol Genet, 18:872-887.

[87] Febbraro F, Sahin G, Farran A, Soares S, Jensen PH, Kirik D, et al. (2013). Ser129D mutant alphasynuclein induces earlier motor dysfunction while S129A results in distinctive pathology in a rat model of Parkinson's disease. Neurobiology of Disease, 56:47-58.

[88] Theodore S, Cao S, McLean PJ, Standaert DG (2008). Targeted overexpression of human alpha-synuclein triggers microglial activation and an adaptive immune response in a mouse model of Parkinson disease. J Neuropathol Exp Neurol, 67:1149-1158.

[89] Chung CY, Koprich JB, Siddiqi H, Isacson O (2009). Dynamic changes in presynaptic and axonal transport proteins combined with striatal neuroinflammation precede dopaminergic neuronal loss in a rat model of AAV alpha-synucleinopathy. J Neurosci, 29:33653373.

[90] Sorrentino ZA, Giasson BI, Chakrabarty P (2019). $\alpha$ Synuclein and astrocytes: tracing the pathways from homeostasis to neurodegeneration in Lewy body disease. Acta neuropathologica, 138:1-21.

[91] Kery R, Chen AF, Kirschen G (2020). Genetic targeting of astrocytes to combat neurodegenerative disease. Neural Regeneration Research, 15:199.

Ortinski PI, Dong J, Mungenast A, Yue C, Takano H, Watson DJ, et al. (2010). Selective induction of astrocytic gliosis generates deficits in neuronal inhibition. Nature neuroscience, 13:584-591.

[93] Li W-W, Yang R, Guo J-C, Ren H-M, Zha X-L, Cheng $\mathrm{J}-\mathrm{S}$, et al. (2007). Localization of alpha-synuclein to mitochondria within midbrain of mice. Neuroreport, 18:1543-1546.

[94] Nakamura K (2013). $\alpha$-Synuclein and Mitochondria: 
Partners in Crime? Neurotherapeutics, 10:391-399.

[95] Hoozemans JJM, van Haastert ES, Eikelenboom P, de Vos RaI, Rozemuller JM, Scheper W (2007). Activation of the unfolded protein response in Parkinson's disease. Biochemical and Biophysical Research Communications, 354:707-711.

[96] Liu M, Qin L, Wang L, Tan J, Zhang H, Tang J, et al. (2018). $\alpha$-synuclein induces apoptosis of astrocytes by causing dysfunction of the endoplasmic reticulum-Golgi compartment. Molecular Medicine Reports, 18:322-332.

[97] Gosavi N, Lee H-J, Lee JS, Patel S, Lee S-J (2002). Golgi fragmentation occurs in the cells with prefibrillar alpha-synuclein aggregates and precedes the formation of fibrillar inclusion. The Journal of Biological Chemistry, 277:48984-48992.

[98] Mori F, Tanji K, Yoshimoto M, Takahashi H, Wakabayashi K (2002). Demonstration of alphasynuclein immunoreactivity in neuronal and glial cytoplasm in normal human brain tissue using proteinase $\mathrm{K}$ and formic acid pretreatment. Experimental Neurology, 176:98-104.

[99] Roberts HL, Brown DR (2015). Seeking a Mechanism for the Toxicity of Oligomeric $\alpha$-Synuclein. Biomolecules, 5:282-305.

[100] Carta AR, Boi L, Pisanu A, Palmas MF, Carboni E, De Simone A (2020). Advances in modelling alphasynuclein-induced Parkinson's diseases in rodents: Virus-based models versus inoculation of exogenous preformed toxic species. Journal of Neuroscience Methods, 338:108685.

[101] Miraglia F, Ricci A, Rota L, Colla E (2018). Subcellular localization of alpha-synuclein aggregates and their interaction with membranes. Neural Regeneration Research, 13:1136.

[102] Schmidt S, Linnartz B, Mendritzki S, Sczepan T, Lubbert M, Stichel CC, et al. (2011). Genetic mouse models for Parkinson's disease display severe pathology in glial cell mitochondria. Human Molecular Genetics, 20:1197-1211.

[103] Subramaniam SR, Vergnes L, Franich NR, Reue K, Chesselet M-F (2014). Region specific mitochondrial impairment in mice with widespread overexpression of alpha-synuclein. Neurobiology of Disease, 70:204213.

[104] Lindstrom V, Gustafsson G, Sanders LH, Howlett EH, Sigvardson J, Kasrayan A, et al. (2017). Extensive uptake of alpha-synuclein oligomers in astrocytes results in sustained intracellular deposits and mitochondrial damage. Mol Cell Neurosci, 82:143156.

[105] Dolgacheva LP, Fedotova EI, Abramov AY, Berezhnov AV (2018). Alpha-Synuclein and Mitochondrial Dysfunction in Parkinson's Disease. Biochemistry (Moscow), Supplement Series A: Membrane and Cell Biology, 12:10-19.

[106] Reeve AK (2012). Relationship Between Mitochondria and $\alpha$-Synuclein: A Study of Single Substantia Nigra Neurons. Archives of Neurology, 69:385.
[107] Arotcarena M-L, Bourdenx M, Dutheil N, Thiolat ML, Doudnikoff E, Dovero S, et al. (2019). Transcription factor EB overexpression prevents neurodegeneration in experimental synucleinopathies. JCI Insight, 4.

[108] Zhang J, Li X, Li J-D (2019). The Roles of Posttranslational Modifications on $\alpha$-Synuclein in the Pathogenesis of Parkinson's Diseases. Frontiers in Neuroscience, 13.

[109] Bruck D, Wenning GK, Stefanova N, Fellner L (2016). Glia and alpha-synuclein in neurodegeneration: A complex interaction. Neurobiol Dis, 85:262-274.

[110] Jeon SG, Kim YJ, Kim KA, Mook-Jung I, Moon M (2018). Visualization of Altered Hippocampal Connectivity in an Animal Model of Alzheimer's Disease. Mol Neurobiol, 55:7886-7899.

[111] Deverman BE, Ravina BM, Bankiewicz KS, Paul SM, Sah DWY (2018). Gene therapy for neurological disorders: progress and prospects. Nat Rev Drug Discov, 17:641-659.

[112] Albert K, Voutilainen M, Domanskyi A, Airavaara M (2017). AAV Vector-Mediated Gene Delivery to Substantia Nigra Dopamine Neurons: Implications for Gene Therapy and Disease Models. Genes, 8:63.

[113] Gaugler MN, Genc O, Bobela W, Mohanna S, Ardah MT, El-Agnaf OM, et al. (2012). Nigrostriatal overabundance of alpha-synuclein leads to decreased vesicle density and deficits in dopamine release that correlate with reduced motor activity. Acta Neuropathol, 123:653-669.

[114] McFarland NR, Lee JS, Hyman BT, McLean PJ (2009). Comparison of transduction efficiency of recombinant AAV serotypes $1,2,5$, and 8 in the rat nigrostriatal system. J Neurochem, 109:838-845.

[115] Burger C, Gorbatyuk OS, Velardo MJ, Peden CS, Williams P, Zolotukhin S, et al. (2004). Recombinant AAV viral vectors pseudotyped with viral capsids from serotypes 1,2 , and 5 display differential efficiency and cell tropism after delivery to different regions of the central nervous system. Mol Ther, 10:302-317.

[116] Taymans JM, Vandenberghe LH, Haute CV, Thiry I, Deroose CM, Mortelmans L, et al. (2007). Comparative analysis of adeno-associated viral vector serotypes $1,2,5,7$, and 8 in mouse brain. Hum Gene Ther, 18:195-206.

[117] Ulusoy A, Bjorklund T, Buck K, Kirik D (2012). Dysregulated dopamine storage increases the vulnerability to alpha-synuclein in nigral neurons. Neurobiol Dis, 47:367-377.

[118] Hammond SL, Leek AN, Richman EH, Tjalkens RB (2017). Cellular selectivity of AAV serotypes for gene delivery in neurons and astrocytes by neonatal intracerebroventricular injection. PLoS One, 12:e0188830.

[119] Aschauer DF, Kreuz S, Rumpel S (2013). Analysis of transduction efficiency, tropism and axonal transport of AAV serotypes 1, 2, 5, 6, 8 and 9 in the mouse brain. PLoS One, 8:e76310.

[120] Chakrabarty P, Rosario A, Cruz P, Siemienski Z, 
Ceballos-Diaz C, Crosby K, et al. (2013). Capsid serotype and timing of injection determines AAV transduction in the neonatal mice brain. PLoS One, 8:e67680.

[121] Maurer AC, Pacouret S, Cepeda Diaz AK, Blake J, Andres-Mateos E, Vandenberghe LH (2018). The Assembly-Activating Protein Promotes Stability and Interactions between AAV's Viral Proteins to Nucleate Capsid Assembly. Cell Rep, 23:1817-1830.

[122] Pillay S, Zou W, Cheng F, Puschnik AS, Meyer NL, Ganaie SS, et al. (2017). Adeno-associated Virus (AAV) Serotypes Have Distinctive Interactions with Domains of the Cellular AAV Receptor. J Virol, 91.

[123] Van der Perren A, Van den Haute C, Baekelandt V (2015). Viral vector-based models of Parkinson's disease. Curr Top Behav Neurosci, 22:271-301.

[124] Wang C, Taki M, Sato Y, Tamura Y, Yaginuma H, Okada Y, et al. (2019). A photostable fluorescent marker for the superresolution live imaging of the dynamic structure of the mitochondrial cristae. Proceedings of the National Academy of Sciences, 116:15817-15822.

[125] Ulusoy A, Musgrove RE, Rusconi R, Klinkenberg M, Helwig M, Schneider A, et al. (2015). Neuron-toneuron alpha-synuclein propagation in vivo is independent of neuronal injury. Acta Neuropathol Commun, 3:13.

[126] Cearley CN, Wolfe JH (2006). Transduction characteristics of adeno-associated virus vectors expressing cap serotypes 7, 8, 9, and Rh10 in the mouse brain. Molecular Therapy, 13:528-537.

[127] Mak SK, McCormack AL, Langston JW, Kordower JH, Di Monte DA (2009). Decreased alpha-synuclein expression in the aging mouse substantia nigra. Exp Neurol, 220:359-365.

[128] Chu Y, Kordower JH (2007). Age-associated increases of alpha-synuclein in monkeys and humans are associated with nigrostriatal dopamine depletion: Is this the target for Parkinson's disease? Neurobiol Dis, 25:134-149.

[129] Soreq L, Consortium UKBE, North American Brain Expression C, Rose J, Soreq E, Hardy J, et al. (2017). Major Shifts in Glial Regional Identity Are a Transcriptional Hallmark of Human Brain Aging. Cell Rep, 18:557-570.

[130] Ellenbroek B, Youn J (2016). Rodent models in neuroscience research: is it a rat race? Dis Model Mech, 9:1079-1087.

[131] Miller IN, Cronin-Golomb A (2010). Gender differences in Parkinson's disease: clinical characteristics and cognition. Mov Disord, 25:26952703.

[132] Picillo M, Nicoletti A, Fetoni V, Garavaglia B, Barone P, Pellecchia MT (2017). The relevance of gender in Parkinson's disease: a review. J Neurol, 264:15831607.

[133] Espa E, Clemensson EKH, Luk KC, Heuer A, Bjorklund T, Cenci MA (2019). Seeding of protein aggregation causes cognitive impairment in rat model of cortical synucleinopathy. Mov Disord, 34:1699-
1710.

[134] Masliah E, Rockenstein E, Veinbergs I, Mallory M, Hashimoto M, Takeda A, et al. (2000). Dopaminergic loss and inclusion body formation in alpha-synuclein mice: implications for neurodegenerative disorders. Science (New York, N.Y.), 287:1265-1269.

[135] van der Putten H, Wiederhold K-H, Probst A, Barbieri S, Mistl C, Danner S, et al. (2000). Neuropathology in Mice Expressing Human $\alpha$-Synuclein. The Journal of Neuroscience, 20:6021-6029.

[136] Kahle PJ, Neumann M, Ozmen L, Müller V, Jacobsen H, Schindzielorz A, et al. (2000). Subcellular Localization of Wild-Type and Parkinson's DiseaseAssociated Mutant $\alpha$-Synuclein in Human and Transgenic Mouse Brain. The Journal of Neuroscience, 20:6365-6373.

[137] Koprich JB, Kalia LV, Brotchie JM (2017). Animal models of $\alpha$-synucleinopathy for Parkinson disease drug development. Nature Reviews Neuroscience, 18:515-529.

[138] Parajuli L, Wako K, Maruo S, Kakuta S, Taguchi T, Ikuno M, et al. (2020). Developmental Changes in Dendritic Spine Morphology in the Striatum and Their Alteration in an A53T $\alpha$-Synuclein Transgenic Mouse Model of Parkinson's Disease. eneuro, 7:ENEURO.0072-0020.2020.

[139] Hendrickx DM, Garcia P, Ashrafi A, Sciortino A, Schmit KJ, Kollmus H, et al. (2021). A New Synuclein-Transgenic Mouse Model for Early Parkinson's Reveals Molecular Features of Preclinical Disease. Molecular Neurobiology, 58:576-602.

[140] Peelaerts W, Bousset L, Van der Perren A, Moskalyuk A, Pulizzi R, Giugliano M, et al. (2015). $\alpha$-Synuclein strains cause distinct synucleinopathies after local and systemic administration. Nature, 522:340-344.

[141] Harms AS, Delic V, Thome AD, Bryant N, Liu Z, Chandra S, et al. (2017). $\alpha$-Synuclein fibrils recruit peripheral immune cells in the rat brain prior to neurodegeneration. Acta Neuropathologica Communications, 5.

[142] Uemura N, Yagi H, Uemura MT, Hatanaka Y, Yamakado H, Takahashi R (2018). Inoculation of $\alpha$ synuclein preformed fibrils into the mouse gastrointestinal tract induces Lewy body-like aggregates in the brainstem via the vagus nerve. Molecular Neurodegeneration, 13:21.

[143] Gómez-Benito M, Granado N, García-Sanz P, Michel A, Dumoulin M, Moratalla R (2020). Modeling Parkinson's Disease With the Alpha-Synuclein Protein. Frontiers in Pharmacology, 11.

[144] Boi L, Pisanu A, Palmas MF, Fusco G, Carboni E, Casu MA, et al. (2020). Modeling Parkinson's Disease Neuropathology and Symptoms by Intranigral Inoculation of Preformed Human $\alpha$-Synuclein Oligomers. International Journal of Molecular Sciences, 21:8535.

[145] Earls RH, Menees KB, Chung J, Barber J, Gutekunst C-A, Hazim MG, et al. (2019). Intrastriatal injection of preformed alpha-synuclein fibrils alters central and peripheral immune cell profiles in non-transgenic 
mice. Journal of Neuroinflammation, 16:250.

[146] Rey NL, Steiner JA, Maroof N, Luk KC, Madaj Z, Trojanowski JQ, et al. (2016). Widespread transneuronal propagation of $\alpha$-synucleinopathy triggered in olfactory bulb mimics prodromal Parkinson's disease. The Journal of Experimental Medicine, 213:1759-1778.

[147] Parr-Brownlie LC, Bosch-Bouju C, Schoderboeck L, Sizemore RJ, Abraham WC, Hughes SM (2015). Lentiviral vectors as tools to understand central nervous system biology in mammalian model organisms. Front Mol Neurosci, 8:14.

[148] Lo Bianco C, Ridet JL, Schneider BL, Déglon N, Aebischer P (2002). $\alpha$-Synucleinopathy and selective dopaminergic neuron loss in a rat lentiviral-based model of Parkinson's disease. Proceedings of the National Academy of Sciences of the United States of America, 99:10813-10818.

[149] Lauwers E, Debyser Z, Dorpe JV, Strooper BD, Nuttin B, Baekelandt V (2003). Neuropathology and Neurodegeneration in Rodent Brain Induced by Lentiviral Vectormediated Overexpression of $\alpha$ Synuclein. Brain Pathology, 13:364-372.

[150] Lauwers E, Beque D, Van Laere K, Nuyts J, Bormans G, Mortelmans L, et al. (2007). Non-invasive imaging of neuropathology in a rat model of alpha-synuclein overexpression. Neurobiol Aging, 28:248-257.

[151] Winner B, Jappelli R, Maji SK, Desplats PA, Boyer L, Aigner S, et al. (2011). In vivo demonstration that alpha-synuclein oligomers are toxic. Proc Natl Acad Sci U S A, 108:4194-4199.

[152] Lo Bianco C, Deglon N, Pralong W, Aebischer P (2004). Lentiviral nigral delivery of GDNF does not prevent neurodegeneration in a genetic rat model of Parkinson's disease. Neurobiol Dis, 17:283-289.

[153] Lo Bianco C, Schneider BL, Bauer M, Sajadi A, Brice A, Iwatsubo T, et al. (2004). Lentiviral vector delivery of parkin prevents dopaminergic degeneration in an alpha-synuclein rat model of Parkinson's disease. Proc Natl Acad Sci U S A, 101:17510-17515.

[154] Mandel RJ, Burger C, Snyder RO (2008). Viral Vectors for In Vivo Gene Transfer in Parkinson's disease: Properties and Clinical Grade Production. Experimental neurology, 209:58-71.

[155] Manfredsson FP, Mandel RJ (2011). The development of flexible lentiviral vectors for gene transfer in the CNS. Experimental Neurology, 229:201-206.

[156] Blumenstock S, Rodrigues EF, Peters F, BlazquezLlorca L, Schmidt F, Giese A, et al. (2017). Seeding and transgenic overexpression of alpha-synuclein triggers dendritic spine pathology in the neocortex. EMBO molecular medicine, 9:716-731.

[157] Mishra J, Jhun BS, Hurst S, J OU, Csordas G, Sheu SS (2017). The Mitochondrial $\mathrm{Ca}(2+)$ Uniporter: Structure, Function, and Pharmacology. Handb Exp Pharmacol, 240:129-156.

[158] Chung WS, Allen NJ, Eroglu C (2015). Astrocytes Control Synapse Formation, Function, and Elimination. Cold Spring Harb Perspect Biol, 7:a020370.
[159] Papouin T, Dunphy J, Tolman M, Foley JC, Haydon PG (2017). Astrocytic control of synaptic function. Philos Trans R Soc Lond B Biol Sci, 372.

[160] Phatnani H, Maniatis T (2015). Astrocytes in Neurodegenerative Disease. Cold Spring Harbor Perspectives in Biology, 7:a020628.

[161] Booth HDE, Hirst WD, Wade-Martins R (2017). The Role of Astrocyte Dysfunction in Parkinson's Disease Pathogenesis. Trends in Neurosciences, 40:358-370.

[162] Tsunemi T, Ishiguro Y, Yoroisaka A, Valdez C, Miyamoto K, Ishikawa K, et al. (2020). Astrocytes Protect Human Dopaminergic Neurons from $\alpha$ Synuclein Accumulation and Propagation. Journal of Neuroscience, 40:8618-8628.

[163] Lee H-J, Suk J-E, Patrick C, Bae E-J, Cho J-H, Rho S, et al. (2010). Direct Transfer of $\alpha$-Synuclein from Neuron to Astroglia Causes Inflammatory Responses in Synucleinopathies. The Journal of Biological Chemistry, 285:9262-9272.

[164] Song YJC, Halliday GM, Holton JL, Lashley T, O'Sullivan SS, McCann H, et al. (2009). Degeneration in Different Parkinsonian Syndromes Relates to Astrocyte Type and Astrocyte Protein Expression. Journal of Neuropathology \& Experimental Neurology, 68:1073-1083.

[165] Braidy N, Gai W-P, Xu Y, Sachdev P, Guillemin GJ, Jiang X-M, et al. (2013). Uptake and mitochondrial dysfunction of alpha-synuclein in human astrocytes, cortical neurons and fibroblasts. Translational Neurodegeneration, 2:20.

[166] Rostami J, Holmqvist S, Lindström V, Sigvardson J, Westermark GT, Ingelsson M, et al. (2017). Human Astrocytes Transfer Aggregated Alpha-Synuclein via Tunneling Nanotubes. The Journal of Neuroscience, 37:11835-11853.

[167] Loria F, Vargas JY, Bousset L, Syan S, Salles A, Melki $\mathrm{R}$, et al. (2017). $\alpha$-Synuclein transfer between neurons and astrocytes indicates that astrocytes play a role in degradation rather than in spreading. Acta Neuropathologica, 134:789-808.

[168] Lee HJ, Suk JE, Patrick C, Bae EJ, Cho JH, Rho S, et al. (2010). Direct transfer of alpha-synuclein from neuron to astroglia causes inflammatory responses in synucleinopathies. J Biol Chem, 285:9262-9272.

[169] Filippini A, Gennarelli M, Russo I (2019). $\alpha$-Synuclein and Glia in Parkinson's Disease: A Beneficial or a Detrimental Duet for the Endo-Lysosomal System? Cellular and Molecular Neurobiology, 39:161-168.

[170] Sheng L, Stewart T, Yang D, Thorland E, Soltys D, Aro P, et al. (2020). Erythrocytic $\alpha$-synuclein contained in microvesicles regulates astrocytic glutamate homeostasis: a new perspective on Parkinson's disease pathogenesis. Acta Neuropathologica Communications, 8:102.

[171] Abounit S, Bousset L, Loria F, Zhu S, de Chaumont F, Pieri L, et al. (2016). Tunneling nanotubes spread fibrillar $\alpha$-synuclein by intercellular trafficking of lysosomes. The EMBO journal, 35:2120-2138.

[172] Dieriks BV, Park TIH, Fourie C, Faull RLM, Dragunow M, Curtis MA (2017). $\alpha$-synuclein transfer 
through tunneling nanotubes occurs in SH-SY5Y cells and primary brain pericytes from Parkinson's disease patients. Scientific Reports, 7.

[173] Budnik V, Ruiz-Cañada C, Wendler F (2016). Extracellular vesicles round off communication in the nervous system. Nature Reviews. Neuroscience, 17:160-172.

[174] Gousset K, Schiff E, Langevin C, Marijanovic Z, Caputo A, Browman DT, et al. (2009). Prions hijack tunnelling nanotubes for intercellular spread. Nature Cell Biology, 11:328-336.

[175] Emmanouilidou E, Elenis D, Papasilekas T, Stranjalis $\mathrm{G}$, Gerozissis K, Ioannou PC, et al. (2011). Assessment of $\alpha$-synuclein secretion in mouse and human brain parenchyma. PloS One, 6:e22225.

[176] Zella MAS, Metzdorf J, Ostendorf F, Maass F, Muhlack S, Gold R, et al. (2019). Novel Immunotherapeutic Approaches to Target AlphaSynuclein and Related Neuroinflammation in Parkinson's Disease. Cells, 8.

[177] Gu X-L, Long C-X, Sun L, Xie C, Lin X, Cai H (2010). Astrocytic expression of Parkinson's disease-related A53T $\alpha$-synuclein causes neurodegeneration in mice. Molecular Brain, 3:12.

[178] Tremblay ME, Cookson MR, Civiero L (2019). Glial phagocytic clearance in Parkinson's disease. Mol Neurodegener, 14:16.

[179] Chavarría C, Rodríguez-Bottero S, Quijano C, Cassina P, Souza JM (2018). Impact of monomeric, oligomeric and fibrillar alpha-synuclein on astrocyte reactivity and toxicity to neurons. Biochemical Journal, 475:3153-3169.

[180] Rappold PM, Tieu K (2010). Astrocytes and therapeutics for Parkinson's disease. Neurotherapeutics: The Journal of the American Society for Experimental NeuroTherapeutics, 7:413423.

[181] Sankar SB, Donegan RK, Shah KJ, Reddi AR, Wood LB (2018). Heme and hemoglobin suppress amyloid $\beta$-mediated inflammatory activation of mouse astrocytes. The Journal of Biological Chemistry, 293:11358-11373.

[182] Foust KD, Nurre E, Montgomery CL, Hernandez A,
Chan CM, Kaspar BK (2009). Intravascular AAV9 preferentially targets neonatal neurons and adult astrocytes. Nature Biotechnology, 27:59-65.

[183] Gray SJ, Samulski RJ (2011). Vector Design and Considerations for CNS Applications.9.

[184] Tong X, Ao Y, Faas GC, Nwaobi SE, Xu J, Haustein MD, et al. (2014). Astrocyte Kir4.1 ion channel deficits contribute to neuronal dysfunction in Huntington's disease model mice. Nature Neuroscience, 17:694-703.

[185] Petrosyan HA, Alessi V, Singh V, Hunanyan AS, Levine JM, Arvanian VL (2014). Transduction efficiency of neurons and glial cells by AAV-1, -5, -9, -rh10 and -hu11 serotypes in rat spinal cord following contusion injury. Gene Ther, 21:991-1000.

[186] Schober AL, Gagarkin DA, Chen Y, Gao G, Jacobson L, Mongin AA (2016). Recombinant AdenoAssociated Virus Serotype 6 (rAAV6) Potently and Preferentially Transduces Rat Astrocytes In vitro and In vivo. Front Cell Neurosci, 10:262.

[187] Srinivasan R, Huang BS, Venugopal S, Johnston AD, Chai $\mathrm{H}$, Zeng $\mathrm{H}$, et al. (2015). $\mathrm{Ca}(2+)$ signaling in astrocytes from Ip3r2(-/-) mice in brain slices and during startle responses in vivo. Nat Neurosci, 18:708717.

[188] Huntington TE, Srinivasan R (2021). Astrocytic mitochondria in adult mouse brain slices show spontaneous calcium influx events with unique properties. Cell Calcium, 96:102383.

[189] Srinivasan R, Lu TY, Chai H, Xu J, Huang BS, Golshani P, et al. (2016). New Transgenic Mouse Lines for Selectively Targeting Astrocytes and Studying Calcium Signals in Astrocyte Processes In Situ and In Vivo. Neuron, 92:1181-1195.

[190] Yang Y-J, Bu L-L, Shen C, Ge J-J, He S-J, Yu H-L, et al. (2020). Fasudil Promotes $\alpha$-Synuclein Clearance in an AAV-Mediated $\alpha$-Synuclein Rat Model of Parkinson's Disease by Autophagy Activation. Journal of Parkinson's Disease, 10:969-979.

[191] Pabon MM, Bachstetter AD, Hudson CE, Gemma C, Bickford PC (2011). CX3CL1 reduces neurotoxicity and microglial activation in a rat model of Parkinson's disease. Journal of Neuroinflammation, 8:9. 